\title{
A PESQUISA EM EDUCAÇÃO: A GESTÃO EDUCACIONAL COMO TEMA DO DEBATE
}

\author{
THE RESEARCH ON EDUCATION: THE EDUCATIONAL \\ MANAGEMENT AS A THEME TO DEBATE
}

\author{
Ramon de Oliveira \\ Doutor em Educação pela Universidade Federal Fluminense. \\ Professor Titular da Universidade Federal de Pernambuco, Recife, PE - Brasil. \\ ORCID: https://orcid.org/0000-0002-2374-2627 \\ ramono@elogica.com.br
}

Resumo: Tendo como referência os impactos que as avaliaçóes realizadas pela CAPES tiveram na dinâmica dos programas de pós-graduação e na produção de teses e dissertaçóes, discute-se a necessidade de a pesquisa em educação ter maior rigor teórico e metodológico e analisar a política educacional de uma perspectiva mais complexa. Metodologicamente, suportados em literatura centrada na pesquisa educacional e na experiência ao longo de 15 anos de orientação a projetos de pesquisa que elegeram a gestáo educacional como tema central de investigaçáo, buscou-se sistematizar uma contribuição para as pesquisas em educação atentarem às dimensões micro e macro, determinantes da realidade escolar.

Palavras-chave: Gestão Educacional. Pesquisa em Educação. Pós-Graduação em Educação. Produtivismo na Pós-Graduação.

Aвstract: Taking as a reference the impacts that the evaluations carried out by CAPES have had on the dynamics of postgraduate programs and the production of theses and dissertations, it is discussed the need for research in education to have greater theoretical and methodological rigor and to analyze policy from a more complex perspective. Methodologically, based on literature focused on educational research and experience over 15 years of orientation to research projects that chose educational management as a central research topic, we sought to systematize a contribution to research in education to address the micro and macro, determinants of school reality.

Keywords: Educational Management. Post-Graduation on Education. Productivism in Post-Graduation. Research on Education. 


\section{Introdução}

Objetivamos apresentar algumas reflexôes sobre a pesquisa em educação, a partir de nossa prática docente em um programa de pósgraduação em educação e na literatura centrada na pesquisa educacional. Elegemos como referência para se pensar a pesquisa educacional trabalhos nos quais a gestão da educação foi temática central de investigação. Nosso objetivo maior é discutir a necessidade de os trabalhos produzidos em programas de pós-graduação em educação primarem pelo rigor teórico-metodológico (ANDRÉ, 2001) e de seus resultados serem socializados com as instituiçóes e os sujeitos investigados. Acreditamos que essa discussão interessa também às outras temáticas de pesquisa na área, e pode contribuir na reflexáo sobre a formaçáo dos estudantes dos nossos cursos de mestrado e doutorado.

No momento no qual desenvolvemos esta reflexão estamos vivenciando os impactos da divulgação do resultado da avaliação quadrienal dos programas de pós-graduação. Essa avaliação, a despeito de ser considerada pela CAPES um importante instrumento de incentivo à melhoria dos cursos de mestrado e doutorado, tem se configurado como mais um momento de estresse na vida dos professores (MOREIRA, 2009). Os programas, ao buscarem posiçôes de sucesso no ranqueamento desenvolvido pela CAPES, sucumbiram a uma lógica produtivista (BIANCHETTI; MACHADO, 2007). Priorizam-se os aspectos quantitativos da produção acadêmica, mas pouco se avançou no sentido da avaliação da qualidade das teses e dissertaçôes, bem como da qualidade da formação dos mestres e doutores. (FERREIRA; ANALICE; CLAUDIO, 2016)

Se pouco sabemos acerca da qualidade das dissertaçóes e teses produzidas, não faltam informaçôes referentes ao tempo de conclusão das investigaçôes, da quantidade de trabalhos publicados em periódicos por docentes e estudantes (cursistas e/ou egressos), do quantitativo de professores cujos trabalhos são publicados em periódicos qualificados em extratos diferenciados etc. Esses dados expressam uma eficiência quantitativa, mas indicam muito pouco sobre a formação de pesquisadores e professores para o ensino superior, muito pouco nos ajudam a avaliar a qualidade das teses e dissertaçôes e, de uma forma geral, a qualidade dos programas. Neste sentido, concordamos com Luciano Mendes de Faria Filho (2016, p. 189) 
quando nos diz, de forma enfática, que “já está mais do que na hora de (nos) insurgirmos coletivamente contra critérios de avaliação que, notoriamente, não servem nem para avaliar a qualidade da formação e, muito menos, a qualidade da produção, mas que têm razoável peso na avaliação dos programas."

A diminuição do tempo de realização das teses e dissertaçôes, articulado à possível falta de rigor nos momentos de avaliação desses trabalhos, em articulação com diversos outros problemas relativos às condiçôes de trabalho nos programas de pós-graduação, têm implicaçóes na qualidade das pesquisas produzidas (KUHLMANN JÚNIOR, 2015), o que não parece afetar a lógica desejada pela CAPES. Para essa instância de avaliação e de fomento da pós-graduação, o fundamental não é o que se produz, mas a quantidade dos produtos e a 'qualidade' dos meios nos quais tais produtos são divulgados. Embora isso possa não ter implicação direta na qualidade da formação dos mestres e doutores, como destacou Macedo (2015), no mínimo podemos questionar até que ponto a busca pela perfomatividade não tem consequência na saúde dos docentes (BIANCHETTI; MACHADO, 2007), na qualidade de seu trabalho e no acompanhamento de seus orientandos e orientandas.

Nessa conjuntura, a preocupação da área de Educação em conseguir mostrar competência, eficiência e produtividade similares às outras áreas do conhecimento parece ter sido resolvida, pois dos 170 programas avaliados na quadrienal (2013-2016), três receberam o conceito 7, ou seja, a área de educação, como poucas áreas, segundo o relatório da CAPES (BRASIL, 2016), consolidou-se como tendo programas de qualidade similar aos maiores e melhores centros de pesquisa do mundo.

A política de expansão dos cursos de mestrado e doutorado parece ter sido bem sucedida, ressaltando-se que a despeito de um sentimento de desconfiança que a área da educação tinha em relação aos mestrados profissionais, a expansão dessa modalidade é inquestionável. De acordo com o Documento da Área da Educação (2016), o quantitativo de programas reconhecidos pela CAPES no ano de 2006 totalizava 78, chegando em setembro de 2016 a 172, expressando um incremento médio de 10 programas anualmente. Esse expressivo crescimento quantitativo também se evidencia no número de teses e dissertaçôes produzidas ao longo dos anos. Quando consultamos, no site da CAPES, o GEOCAPES (www. 
geocapes.capes.gov.br) observamos que em 2008 foram titulados 2.482 mestres e 659 doutores em educação. Já no ano de 2015, último ano para o qual estão disponibilizadas as informações, foram titulados 2.975 mestres e 1.111 doutores

Quando consideramos esses dados, uma questão se coloca: a contribuição dos programas à melhoria da qualidade da escola pública. Entendemos que uma das maiores contribuiçóes dos programas de educação refere-se à sua interlocução com as redes públicas de ensino. Principalmente dando a elas o retorno dos resultados das pesquisas realizadas por seus mestrandos e doutorandos. Mesmo existindo o quesito 'inserção social do programa' como um dos itens de avaliação, essa interlocução não tem sido objetivada pela sistemática de avaliação. $\mathrm{O}$ alvo da socialização das pesquisas ali produzidas é o público que acessa os periódicos e não os próprios sujeitos das pesquisas: professores, alunos, gestores escolares e demais sujeitos da comunidade escolar.

Essa debilidade não é nova para os programas de pós-graduação em educação. Bernadete Gatti (GATTI, 2001), em artigo publicado nos Cadernos de Pesquisa da Fundação Carlos Chagas, ao relatar a análise que fizera sobre o quanto as pesquisas nas universidades contribuíram para as reformas e inovaçóes ocorridas na educação básica, destacou a falta de divulgação das pesquisas acadêmicas como um dos elementos atestadores do pouco envolvimento da universidade com as redes públicas de ensino. Para ela, essa constataçáo não expressava um descompromisso das universidades com a educação básica, mas o fato de que essa relação precisava ser discutida.

A razão de ser dos cursos de mestrado e doutorado está naquilo que produzem de conhecimento novo, no que ajudam a pensar novas práticas e soluçóes para enfrentar os desafios de fazer das escolas públicas espaços efetivamente voltados para a maioria da população, principalmente a que vivencia séculos de marginalidade e exclusão social. No nosso entender, ter sempre clara a função da pós-graduação é uma das imposiçôes para pensar quanto ela pode contribuir para fazer da educação pública algo bem melhor do que tem sido até o momento, seja a educação básica seja a de nível superior. Na mesma direçáo, entendemos ser importante destacar a importância de a escola pública, principal espaço de nossas investigaçóes, ser priorizada na socialização dos resultados das pesquisas. 
Essa postura é uma estratégia para o fortalecimento do papel da pós-graduação em educação, valorizando sua contribuição para a melhoria da qualidade das escolas dos setores majoritários da população. A defesa da democratização do acesso à escola, a constituição de mecanismos participativos da gestáo escolar e o aumento do financiamento público da educação, no nosso entender, articulam-se à necessidade de a academia criar mecanismos de retornar sua produção àquela que é a razáo de ser das pesquisas dos programas de pós-graduação em educação.

Considerando esse contexto, passemos a discutir a pesquisa em educação, centrando nosso debate na importância do rigor teórico-metodológico e na importância de essas pesquisas contribuírem para a melhoria da escola pública, daí nossa preocupação de que os resultados dessas investigaçóes sejam socializados com as instituiçóes e sujeitos alvos.

Metodologicamente, tendo como referência uma literatura centrada na pesquisa educacional (ALVES-MAZOTTI, 2001; ANDRÉ, 2001; GATTI, 2001; SÁNCHEZ GAMBOA, 2003; SEVERINO, 2001, 2009; VAN ZANTEN, 2004) e na política educacional (AFONSO, 2001; FERREIRA, 2008; FERREIRA; AGUIAR, 2009; DE FREITAS, 2012; NEVES, 2005; OLIVEIRA, 2009) e a experiência ao longo de 17 anos na orientação de projetos de pesquisa que elegeram a gestão educacional como tema central de investigaçáo, buscou-se sistematizar uma contribuição para as pesquisas em educação atentarem às dimensóes micro e macro, determinantes do fazer educacional.

\section{Começando a conversa...}

Desde 2001 temos trabalhado com alunos recém-ingressados no Programa de Pós-Graduação em Educação, em uma linha de pesquisa denominada 'Política Educacional, Planejamento e Gestão da Educação'. Estamos sempre diante do desafio de ajudar nas orientaçôes iniciais de projetos de dissertação com temáticas as mais variadas. Nas turmas, é recorrente a presença de, pelo menos, um ou dois projetos direcionados à gestáo da educação.

Os mestrandos normalmente direcionam seus projetos para tentar encontrar as implicações da gestão educacional em alguns fenômenos que 
ocorrem no interior da escola ou no âmbito do sistema municipal ou estadual de ensino. Muitas vezes, quando a temática gestão é tida como central na investigação, os mestrandos procuram direcionar suas investigaçóes para as implicaçóes da gestão democrática no cotidiano da escola.

Em um levantamento das dissertaçôes produzidas a partir do ano 2002, nas quais encontramos a gestão da educação como uma de suas palavras-chave, constatamos a existência de temáticas e problemáticas de pesquisa diversas como: política de valorizaçáo do magistério, participação popular na definição da política municipal de educação, Plano de Desenvolvimento da Escola (PDE), conselho escolar e gestão do ensino superior. Além dessas, é possível perceber, como destacamos anteriormente, dissertaçôes que se direcionaram a investigar a implantação da gestão democrática em sistemas municipais e estaduais de ensino.

Essa informação é importante para confirmar que a temática gestão, embora tenha passado a se configurar como alvo de atenção nas dissertaçóes e teses de doutorado, não tem restringido os pesquisadores a considerarem a gestão educacional apenas como a prática da administração da escola ou dos sistemas municipais e estaduais de ensino. As pesquisas tendem a ir mais além da investigação sobre a gestão, isto é, elas passam a colocar as políticas educacionais, nas mais variadas expressóes de sua materialização, como alvo de investigaçáo, postura que consideramos política e metodologicamente correta. Se desejamos que nossos trabalhos de investigação contribuam para a constituição de uma educação pública de melhor qualidade, não podemos nos deixar levar por interpretaçóes reducionistas dos problemas da educação pública a um mero problema de gestão (MELLO, 1994). Como Afonso (2001) nos ajudou a refletir, o desejo de contribuir para uma nova realidade da educação pública, articula-se ao movimento de considerar a amplitude de determinantes da política educacional.

Não podemos aceitar interpretaçôes apressadas que, ao compararem as diferenças de qualidade entre escolas públicas e privadas, concluem que as diferenças nos resultados de aprendizagem dizem respeito apenas às formas de gestão dessas redes. Respostas desse tipo intencionam muito mais a apologia da iniciativa privada do que, propriamente, a melhoria da qualidade da escola pública (JIMENEZ; LOCKHEED, 1995). Qualquer pessoa com um mínimo de bom senso reconhecerá a 
importância do gestor para a consolidação de um projeto pedagógico consistente, bem com sua importância enquanto agente estimulador dos professores e outros profissionais da educação no enfrentamento das inúmeras dificuldades e desafios postos para a escola pública. No entanto, é um reducionismo bizarro deixar de levar em consideração a variedade de dificuldades vivenciadas pelas escolas públicas, as quais não podem ser superadas apenas em função das ações individuais de seus gestores, mesmo sendo estas fundamentais.

Embora achemos importante destacar e ressaltar o papel de alguns gestores escolares na condução de sua equipe de profissionais da educação, na relação estabelecida com alunos e seus pais e o quanto se afirmam como lideranças nas comunidades na quais estão inseridas as escolas, esses têm seu trabalho reconhecido em virtude de haver um consenso segundo o qual as dificuldades são tão grandes que um bom resultado é uma exceção e, portanto, passível de destaque. Os premiados ou reconhecidos por resultados satisfatórios de suas escolas, destacam-se, talvez, por ser consensual o quanto é difícil se conquistar resultados diferentes caso não se modifique o panorama de financiamento da educação pública brasileira. (CARREIRA; PINTO, 2007)

Sempre é importante lembrar-se de outras questôes que, se não dizem respeito diretamente à escola, têm uma repercussão direta nos resultados obtidos pelo sistema educacional: violência, marginalidade e desemprego juvenil, condiçóes econômicas e desestrutura familiar etc. E todas elas estão no âmbito da responsabilidade estatal. Algumas terão melhor resolução a partir de políticas governamentais e outras não. Algumas estão no raio de ação do gestor escolar e outras não.

O método científico é o meio pelo qual se pode decifrar os fatos que não são transparentes, pois seu sentido objetivo deve ser revelado pela ciência. Científico será o pensamento que não se contente com a forma como o acontecimento se manifesta pela situação, mas o questiona. Constrói-se a partir da investigação dos fatos reais, distinguindo-se o que é "essencial" do que é “acessório”. Ficar no essencial é necessário para romper com as representações ilusórias imediatas. (GOHN, 2005, p. 255) 
Ainda que sempre destaquemos a importância da destinação de maiores recursos para as escolas públicas e uma maior valorização dos profissionais da educação, somente isso, embora indispensável e prioritário, não garantirá a melhoria da escola pública, haja vista o montante de desafios e desestruturaçôes que afetam o sistema público de ensino, para o qual recorre a maioria da populaçáo vitimada pelas principais mazelas sociais brasileiras. A importância de se pensar a gestáo e as políticas educacionais, articulando-as à responsabilidade estatal com o financiamento da educação pública, é de fundamental importância. Tendo por base essa articulação consegue-se superar as explicaçôes limitadas à valorização de práticas individuais para a compreensão do quadro atual da educação pública, A valorização dessas práticas não pode obscurecer os fatores que, mesmo determinantes do cotidiano escolar, estruturam-se em espaços longínquos do dia-dia da escola e, por conseguinte, fora da alçada e do controle do gestor escolar.

O gestor se depara com problemáticas relativas ao financiamento da educação, aos valores a serem perseguidos pelos currículos escolares e à inexistência de políticas de valorização dos profissionais da educação, as quais têm uma repercussáo direta no fazer cotidiano da escola e influenciam diretamente o sucesso da gestão escolar. A interdependência à qual está submetida a prática do gestor inibe, caso queiramos ser metodologicamente consequentes, a avaliação da prática de gestão tendo como referência apenas o cotidiano. Se assim procedemos, tendemos a deixar de reconhecer que o cotidiano escolar não é a totalidade e nem é a pura expressão da prática sobre a qual a teoria deve ser estruturada.

As dimensões da prática educativa, especificamente do sistema público de ensino, abrangem relaçôes espaciais e de poder que ultrapassam os muros da escola. Ela se estrutura a partir do projeto de formaçáo de naçáo objetivando ser posto em prática pelas classes ou fraçóes de classe no poder. A escola e tantos outros aparelhos de Estado, reconhecidas suas peculiaridades, possibilidades e objetivos específicos, articulam-se, respondendo a contento ou náo, a esse projeto previamente estabelecido. Logo, o que se materializa na cotidianidade das escolas não é apenas a expressão da prática dos docentes e gestores, mas, sim, uma das dimensóes da materialização do projeto educativo perseguido pela atual classe no poder e que o Estado, enquanto agente educador, mobiliza-se na perspectiva de imple- 
mentar uma nova pedagogia da hegemonia (NEVES, 2005). Com relação a essa perspectiva, Neves e Sant'anna (2005, p. 26) assim discorrem:

Sob a hegemonia burguesa, o Estado capitalista vem realizando a adaptaçáo do conjunto da sociedade a uma forma particular de civilização, de cultura, de moralidade. No decorrer do século XX, diante das mudanças qualitativas na organização do trabalho e nas formas de estruturação do poder, o Estado capitalista, mundialmente, vem redefinindo suas diretrizes e práticas, com o intuito de reajustar suas práticas educativas às necessidades de adaptaçáo do homem individual e coletivo aos novos requerimentos do desenvolvimento do capitalismo monopolista.

O conflito interno das classes no poder, a contínua reestruturação do Estado objetivando dar conta da disputa entre as classes e fraçóes de classe que o cortam de lado a lado (POULANTZAS, 1981) se materializam nas práticas escolares, no financiamento da educação e nas políticas educacionais. Logo, analisar as práticas estruturadas no interior da escola descoladas das relaçóes de poder estruturadas na sociedade é um reducionismo metodológico, o qual terá por conseqüência o encontro de soluções técnicas ou individuais para questôes cujo enfrentamento correto depende da consideração da totalidade dos fatores determinantes do dia-a-dia da escola.

A realidade, enquanto dialética, implica o reconhecimento da necessidade de sua apreensão como um todo, um todo estruturado que se desenvolve e se recria. O conhecimento dos fatos ou do conjunto dos fatos da realidade significa conhecer o lugar que eles ocupam na totalidade, o próprio real. (GOHN, 2005, p. 256)

Pensar a análise da gestão e as políticas educacionais a partir desses pressupostos implica referenciar-nos em um construto teórico que explicite a ação estatal no âmbito de contradições entre classes e fraçóes em disputa por sua atenção e priorização. A política educacional está imersa num 
contínuo movimento de definição, seja pelo confronto estabelecido entre classes antagônicas em relação à propriedade desigual dos meios de produção e das produçôes materiais e imateriais existentes seja pelo esforço do capital de fazer os espaços não econômicos tornarem-se suscetíveis a modificações necessárias ao seu movimento de recomposição das taxas de lucro e de hegemonia ideológica e política. Há sempre de levar em consideração que a atuação do Estado na área educacional é uma síntese de relaçóes de contradição que se estabelecem a partir das contradiçôes de classe no interior da nação brasileira e, ao mesmo tempo, sem desvinculação desses conflitos internos, também é diretamente determinada pela relação de perda de autonomia que o Estado brasileiro vivencia no atual processo de mundialização do capital.

As políticas educacionais, até muito recentemente, eram políticas que expressavam uma ampla autonomia de decisão do Estado, ainda que essa autonomia fosse, necessariamente, a resultante das relações (complexas e contraditórias) com as classes sociais dominantes, e fosse igualmente sujeita às demandas das classes dominadas e de outros actores colectivos e movimentos sociais. Todavia, ainda que, cada vez mais, haja indicadores que apontam para uma crescente diminuição dessa autonomia relativa, continua a ser necessário fazer referência ao papel e lugar do Estado nação, mesmo que seja para melhor compreender a sua crise actual e a redefiniçáo do seu papel - agora, necessariamente, tendo em conta as novas condicionantes inerentes ao contexto e aos processos de globalização e transnacionalização do capitalismo. (AFONSO, 2001, p.16)

Nesse sentido, quanto mais as dissertaçóes e teses voltadas para a análise da gestão educacional forem estruturadas tendo como referência o movimento de reprodução do capital ao nível global e o papel da nação brasileira na divisão internacional do trabalho, mais capazes serão de ampliar o raio de investigação e de interpretação da realidade educacional. Dessa forma, melhor captaráo a materialidade da gestáo escolar. Construir esse movimento analítico implica perseguir um norteamento teórico desvelador das relaçóes de poder e de força que o capital estabelece no mo- 
mento atual de seu processo de reprodução, mas significa também estruturar no processo de investigação um movimento metodológico capaz de dar conta da dialeticidade do processo educativo. Ou seja, considerar que a escola, por um lado, serve aos interesses de reprodução do capital, mas contraditoriamente, por outro, pode contribuir para a construção de uma nova ordem social.

A gestão no interior desse processo não é neutra nem marginal. Ela é expressão das contradiçôes nas quais está imersa a escola, bem como das contradiçóes e conflitos existentes em seu interior. Nesse sentido, para a apreensão desse real, é necessário um método cujo pressuposto seja a dialeticidade das relaçôes sociais. Daí a ciência não só se faz necessária, como é pré-condição de apreensão do real.

O que torna a ciência necessária é o fato de a realidade não ser transparente. A aparência e a essência dos fenômenos não coincidem, embora uma revele elementos da outra. Portanto, o que é dialético é a própria realidade; por isso, precisamos de instrumentos que captem essa dialética, ou seja, um método de abordagem adequado à própria natureza dos fenômenos e fatos sociais, enquanto objetos de investigação.

O método científico é o meio pelo qual se pode decifrar os fatos que não são transparentes, pois seu sentido objetivo deve ser revelado pela ciência. Científico será o pensamento que não se contente com a forma como o acontecimento se manifesta pela situação, mas o questiona. (GOHN, 2005, p. 255)

Essa compreensão da possibilidade de apreensão do real pressupóe que as relaçóes sociais, inclusive as materializadas no interior da escola, não podem ser aprendidas, na sua totalidade, pela utilização de técnicas de investigação descoladas de um referencial epistemológico que dialogue com o real a partir de sua especificidade e de suas tramas não reveladas. Logo, "é o movimento dos fenômenos que determina os instrumentos que irão captá-los e não o inverso." (GOHN, 2005, p. 259). Os instrumentais metodológicos e a teoria náo determinam o movimento da realidade e nem toda teoria ou metodologia é capaz de aprofundar-se no movimento do real e aproximar-se de sua essência. Os pressupostos para pesquisa em 
gestão que aqui levantamos concretizam-se à medida que o movimento de investigação se estrutura como um diálogo crítico voltado à compreensão do todo estruturado, no qual a gestâo se insere. Tendo sempre como referência as contradiçôes e as relaçôes de poder determinantes do fazer cotidiano da escola, bem como das próprias práticas de gestão. Como nos alertou Antônio Joaquim Severino (2001, p. 19):

[...] um conhecimento sobre a educação que se pretenda rigoroso e científico não pode deixar de levar em consideração as forças de opressão e de dominação que atuam na rede das relaçóes sociais, que faz da sociedade humana uma sociedade política, hierarquizada e atravessada pelo poder de pela dominação. Todo conhecimento que tem a ver com a educação não pode deixar de enfrentar, de modo temático explícito, a questão do poder, elemento que marca incisivamente toda expressão concreta da existência humana.

Tendo essa perspectiva de investigação, a estruturação do processo metodológico ultrapassa a síntese, em algumas páginas da tese ou da dissertação, dos passos a serem perseguidos e as técnicas de levantamento 
emitidos por professores ou alunos quando os mesmos são alvos de nossas investigaçôes.

Por dificuldade de distanciamento, muitas vezes mestrandos e doutorandos assumem como verdadeiras e inquestionáveis as falas dos professores. Sabedores da pouca responsabilidade estatal para com a educação, torna-se quase impossível não se deixarem levar pelo discurso comum, embora verdadeiro, de que as debilidades existentes no sistema educacional decorrem do descompromisso do Estado, tanto no referente ao financiamento da educação quanto na valorização dos profissionais do magistério. Assim, na análise do discurso governamental e na dos professores, alunos e gestores deve haver o compromisso do investigador de apontar as contradiçóes existentes e pautar-se sempre pelo objetivo de vislumbrar a coerência entre o discurso e a prática do sujeito pesquisado. Sáo inconcebíveis as dissertaçôes e teses construídas tendo por base um amontoado de falas, objetivando fortalecer a visão do professor como vítima e do governo como algoz, como se alguns professores não fossem capazes de estabelecer rituais e práticas extremamente prejudiciais à tentativa de um governante de tornar a escola melhor. Muitas vezes cai-se em uma pseudodemocracia ao procurar fazer com que a dissertação ou a tese seja espaço para os 'oprimidos' poderem ter o direito de expressar-se, como destacou a professora Alda Judith Alves-Mazzotti (2001, p. 43):

[...] o que temos visto é que muitas pesquisas, sob a alegação de "dar voz" aos sujeitos ou de valorizar as práticas, limitamse a reproduzir falas e falas dos sujeitos, sem qualquer tentativa de identificar regularidades, relaçôes e categorias e/ou se servir de um instrumental analítico capaz de organizar e dar sentido aos dados. A crescente valorização da prática e da subjetividade parece estar levando a uma tendência à reificação da prática e do sujeito, em prejuízo da construção de conhecimentos relevantes e do diálogo com os autores que já se ocuparam do tema.

O recheio do relatório de pesquisa com depoimentos sem uma devida análise, além de expressar a fragilidade do trabalho, não contribui nem um pouco para a mudança das práticas de opressão vivenciadas por 
esses sujeitos. A possibilidade concreta de mudança dessa realidade se estabelece pela investigação das causas dos sujeitos serem excluídos e das suas vozes serem silenciadas (ALVES-MAZZOTTI, 2001). A pesquisa náo deve ter o intuito de encontrar uma verdade nas falas dos sujeitos entrevistados. Mais importante para o pesquisador é encontrar os nexos que nos ajudam a entender as relaçóes estabelecidas, é entender como os diversos sujeitos intervêm no processo educativo. Um depoimento, embora não seja sinônimo de verdade, é um indício, uma pista para o entendimento das dinâmicas ocorridas na escola e que a fazem ser o que é. A entrevista nos ajuda a construir a compreensão de um processo coletivo e nos habilita, a partir de um certo distanciamento, a articular práticas e discursos formadores e definidores do projeto concretizado na escola. Por mais que as entrevistas sejam capazes de explicitar e comprovar as sínteses às quais chegamos no processo de investigação, devemos ter a clareza que elas são produtos de nosso entendimento, de nossa interpretação. A realidade não se apresenta tal qual nós entendemos que ela seja. O fundamental é exatamente saber como os indivíduos, a partir de seu pensar, atuam na construçáo do objeto investigado.

O que nos importa não é tanto se o que os atores estáo dizendo é verdadeiro ou falso, mas saber que têm atitudes diferentes. Pouco importa se em sala de aula a interpretação do professor é mais verdadeira que a dos alunos, porque sabemos que os alunos, mesmo que sua interpretação seja falsa, vão atuar segundo esta interpretação. (VAN ZANTEN, 2004, p. 36)

A investigação nos proporciona, inclusive a partir das entrevistas, chegar a entendimentos, sínteses, conclusões e avaliaçôes que são para nós verdades provisórias, em virtude de serem produtos de um tratamento rigoroso das informaçóes colhidas. Estas 'verdades' estruturaram-se a partir de medos, desejos, desilusôes, insatisfaçôes etc., na maioria das muitas vezes ocultos nos depoimentos dos pesquisados.

A análise da política e educacional e da gestão deve pautar-se na compreensão de que não há vítimas ou algozes na escola, mas sim atores que, a partir de suas possibilidades e do poder construído, edificam uma escola de forma a atender a seus interesses corporativos, individuais ou 
de classe. Essa análise precisa ter como pressuposto ético e político que a escola, para ser diferente, precisa contar com recursos financeiros suficientes para professores e gestores desenvolverem seus trabalhos, não a partir de sua genialidade ou de seu comprometimento social e político fora do comum, mas a partir de condições que permitam a articulação entre competência técnica e compromisso profissional com a escola pública. E fazer disso o suficiente para a escola responder positivamente ao seu papel social e político.

A investigação sobre a gestão demanda, antes de tudo, um movimento de ampliação do horizonte epistemológico. Essa ampliação se estrutura principalmente, mas náo exclusivamente, pelo contato com a realidade escolar e pelo contato com bibliografia interessada na gestáo da educação ou nas políticas educacionais. Agir metodologicamente, de forma conseqüente, é não esquecer que na escola materializa-se a síntese de relaçôes de poder e de disputa em vigor na sociedade, no âmbito do Estado e no interior da própria escola (AZEVEDO, 2004). Consequentemente, a prática de gestão escolar ou de sistemas institui-se a partir da busca do gestor de atender ou de se manter na seara de contradiçóes e de conflitos na qual sua gestão está imersa.

Para além destas questóes, importa assinalar que a existência de um comprometimento político, ainda que seja primordial, não dá direito ao pesquisador de negligenciar o compromisso científico de produção de um conhecimento novo e de avanço nas discussóes referentes à temática de pesquisa a qual se dedica. Como nos alertou a professora Marli André (2001), não é em função da temática escolhida que se definirá a importância da pesquisa efetivada, pois há muitas coisas na educação merecedoras de investigação. $O$ fundamental é o rigor no processo de investigação. Isso, no nosso entender, marca e a peculiaridade de qualquer trabalho de mestrado ou de doutorado.

[...] as questôes a serem perseguidas na área de educação são ainda tantas e de tamanha variedade que não podemos nos perder em polêmicas que só nos deixarâo cada vez mais distantes da realidade. São tantas as perguntas relevantes que ainda não foram formuladas, tantas as problemáticas que ainda precisamos conhecer, que sobram espaços para todo tipo de investiga- 
ção, desde que se cuide da sistematização e controle dos dados, que o trabalho de pesquisa seja devidamente planejado, que os dados sejam coletados mediante procedimentos rigorosos, que a análise seja densa e fundamentada e que o relatório descreva claramente o processo seguido e os resultados alcançados. (ANDRÉ, 2001, p. 57)

A existência de pesquisas anteriores sobre a temática eleita não é impeditivo de novas investigaçóes, muito ao contrário. Os trabalhos já produzidos são as bases a partir das quais o pesquisador conhece o que já foi produzido e descobre o que ainda merece ser feito. Nesse sentido, estar atento ao realizado anteriormente, não é apenas uma obrigação ética e técnica do investigador, mas é um processo fundamental na construção de sínteses iniciais no processo de investigação, como nos alertou Gonçalves (2002, p. 236):

Ler e analisar o que produziram outros pesquisadores, que anteriormente pesquisaram realidades e fatos de alguma forma semelhantes a seu objeto de estudo, possibilita ao pesquisador selecionar tudo aquilo que possa servir em sua pesquisa. Apropriando-se desses conhecimentos e articulando-os aos que já possui - decorrentes de sua experiência pessoal, de sua trajetória de vida -, refina suas perspectivas teóricas, aguça a percepção de seus próprios valores, torna mais articuladas suas intençôes, aclara e objetiva seu "aparelho conceitual.

Ao mesmo tempo, esse diálogo é o reconhecimento de que não pensamos sozinhos, mas que chegamos a conclusóes a partir de um fecundo debate com a realidade, mediado por um conjunto de conhecimentos postos à disposição por personagens, após investigações, muitas vezes, com questionamentos e/ou procedimentos próximos aos nossos. O fundamental desse diálogo é reconhecer que a realidade para a qual direcionamos nosso olhar precisa ser melhor entendida e, para isso acontecer, precisamos admitir que embora exista a peculiaridade da realidade pesquisada há a universalidade da temática de pesquisa. 
Como expressou Alves-Mazzotti (2001), não se trata simplesmente de trazer uma bibliografia para o interior do trabalho, mas de estabelecer uma interlocução, evidenciando que nossa problemática é fruto de um prévio processo investigativo. Isso sim permite ao trabalho contribuir para formulação de novas teorias.

Quando enfatizo a importância dessa contextualização do problema por meio do diálogo com estudos anteriores, não me refiro à "revisão da bibliografia", que arrola autores e mais autores, usando a fórmula burocrática” segundo fulano”, "para beltrano", deixando de fora o autor da pesquisa e não evidenciando sua funcionalidade na discussão dos resultados. Quando falo em diálogo, refiro-me à comparação e à crítica que explicitam inicialmente a necessidade e pertinência do estudo proposto, e, ao seu final, apontam corroboraçóes e discordâncias entre os resultados obtidos e os estudos anteriores. Tais procedimentos não são formalismos acadêmicos, são condiçôes necessárias à cumulatividade e transferibilidade do conhecimento, assim como à formulação de teorias. (ALVESMAZZOTTI, 2001, p. 42)

Produzir um conhecimento novo ou garantir ineditismo não ocorrerá em função da escolha de um campo de pesquisa, uma escola ou uma rede que nunca foram alvos de investigação. Ineditismo é algo conseguido pela construção do argumento do trabalho, ou seja, a partir de uma boa questão de pesquisa, do estabelecimento de objetivos pertinentes, da maturidade no trato da literatura disponível, principalmente no momento de análise dos dados. São essas as características de um trabalho de investigação em nível de mestrado e doutorado que fazem dele uma referência para outros investigadores.

Compreendendo o papel e a importância das pesquisas sobre a gestão escolar e a política educacional é fundamental que, além do rigor metodológico e científico, os pesquisados se vejam na investigação. É indispensável permitir aos pesquisados discordarem, questionarem, aprenderem, pensarem junto com o pesquisador. Para isso, é necessário o estabelecimento de um diálogo maduro e autônomo com os sujeitos de nossa 
investigação, o que não se concretiza se não formos capazes de garantir a democratização do acesso às pesquisas realizadas nas escolas. Essa tem sido uma das maiores lacunas ou debilidades dos programas de pós-graduação em educação.

Investigar as práticas de gestão escolar ou a materialização das políticas educacionais é uma tentativa de tornar compreensíveis os ambientes escolares para os que, mesmo sem terem postos os pés nela, reconheçam sua importância. Politicamente deve haver o compromisso de que o falar da escola seja cada vez menos a partir do senso comum. O trabalho acadêmico não deve ter um fim em si mesmo. Deve-se objetivar desde o início de sua confecção que seus resultados possam ser apreciados e discutidos com o maior número de pessoas, de forma a contribuir para uma mudança qualitativa da escola. O valor principal do conhecimento produzido está no quanto ele contribui para a transformaçáo do real.

O grau de qualidade acadêmica é proporcional à proximidade com a práxis, com a possibilidade da aplicação dos resultados e com a intervenção sobre a realidade diagnosticada. Se a pesquisa toma como ponto de partida os problemas concretos, e consegue elaborar diagnósticos concretos, a sua eficácia está em fornecer critérios de ação e de intervenção. Neste sentido, acredito que a contribuição da pesquisa seja qualitativa ou quantitativa, seja na vertente fenomenológica, etnográfica ou dialética, se coloca no grau de contribuição no diagnóstico e transformação da realidade. (SÁNCHEZ GAMBOA, 2003, p. 404)

Não tem sentido que algo tão precioso quanto as pesquisas sobre educação permaneçam 'inacessíveis' à população. Pode-se objetar a essa observação o fato de as pesquisas estarem em revistas, livros e internet. Tal argumentação é incoerente com a realidade de um país com um contingente substantivo de pessoas excluídas desses meios de comunicação e que em virtude do seu baixo nível de escolarização teriam dificuldade de acessar ou compreender tais informaçóes. Deveríamos buscar uma articulação com os gestores escolares de forma a viabilizar, para as comunidades escolares, a socialização das pesquisas realizadas a partir delas e com elas. 
É importante tornar essas investigações uma contribuição para pais, alunos e professores intervirem melhor na gestáo escolar, fortalecendo a possibilidade da gestão democrática (FERREIRA, 2008; OLIVEIRA, 2009; FERREIRA; AGUIAR, 2009). Essa preocupação não deve ser apenas dos investigadores, mas deve fazer pauta da agenda dos programas de pósgraduação em educação.

Muitas vezes são realizadas investigaçôes de muito boa qualidade e que podem representar uma ótima contribuição para os gestores dos sistemas de ensino. No entanto, a possibilidade de tal fato se concretizar é muito pequena e demanda a existência de uma política de aproximaçáo entre as pós-graduaçóes e os sistemas de ensino de forma que os resultados possam ser socializados e se crie uma cultura de debates permanentes envolvendo universidades, professores, gestores escolares e sistemas, além de todos aqueles interessados na problemática educacional.

\section{Consideraçóes finais}

As pesquisas voltadas para a temática da gestão escolar ou das políticas educacionais devem ter um compromisso ético e político de fazer da escola e da educação como um todo um local acessível a todo cidadão. As pesquisas sobre a escola, particularmente as que objetivem dar conta de seus mecanismos de funcionamento ou das relaçóes de poder que a atravessam, são fundamentais para se criar uma nova visão sobre os profissionais da educação.

Perceber as múltiplas contradições nas quais está envolvida a escola permitirá à sociedade visualizar o professor como um cidadão de direitos, como um profissional que enfrenta uma multiplicidade de barreiras para poder exercer sua profissão. Talvez com esse abrir da 'caixa preta' chamada escola possamos apontar, num futuro não muito distante, para práticas de gestão efetivamente democráticas. Não apenas pela intencionalidade de alguns gestores, mas pela convicção da sociedade de que só podemos ter uma escola diferente na medida em que ela participar do seu dia-a-dia, interferindo no seu funcionamento, construindo seu projeto político-pedagógico, definindo suas prioridades, elaborando seu currículo e, antes de tudo, sentindo-se na obrigaçáo de confrontar-se 
diretamente com o poder governamental para garantir à escola o exercício de sua função social e política na perspectiva da construção de uma ordem mais fraternal e democrática.

\section{Referências}

AFONSO, Almerindo Janela. Reforma do estado e políticas educacionais: entre a crise do estado-nação e a emergência da regulação supranacional. Educação e Sociedade, Campinas, n.75, p.15-32, ago. 2001.

ALVES-MAZOTTI, Alda Judith. Relevância e Aplicabilidade da Pesquisa em Educação. Cadernos de Pesquisa, São Paulo, n.113, p.39-50, jul. 2001.

ANDRÉ, Marli. Pesquisa em Educação: buscando rigor e qualidade. Cadernos de Pesquisa, São Paulo, n. 113, p. 51-64, jul. 2001

AZEVEDO, Janete M. Lins. A educação como Política Pública. 3. ed. Campinas, SP: Editora Autores Associados, 2004.

BIANCHETTI, Lucídio; MACHADO, Ana Maria Netto. "Reféns da produtividade" sobre produção do conhecimento, saúde dos pesquisadores e intensificação do trabalho na pós-graduação. 2007. Disponível em: <http://30reuniao.anped.org.br/trabalhos/GT093503--Int.pdf>. Acesso em: 27 jul. 2017 Nível Superior. Documento de Área 2016 - Educaçáo. Brasília, 2016. Disponível em: <https:// http://avaliacaoquadrienal.capes.gov.br/documentos-de-area>. Acesso em: 28 jun. 2017.

CARREIRA, Denise; PINTO, J. M. R. . Custo Aluno-Qualidade Inicial: rumo à educação pública de qualidade no Brasil. São Paulo: Global, 2007. Disponível em: < http://www.campanhaeducacao.org.br/?pg=Publicacoes\&id=18>. Acesso em: 23 set. 2010.

FARIA FILHO, Luciano Mendes de. Avaliação da Pós-Graduação em Educação: questôes, dilemas e algumas proposiçôes. Educação em Foco, v. 19, n. 27, p. 173-205, jan./jun. 2016.

FERREIRA, Carla Guimarães; ANALICE Valdman de Miranda; CLAUDIO Roberto Marques Gurgel. Consequências do Produtivismo Acadêmico para a Vida Docente. Revista Brasileira de Administração Política, Salvador, v. 8, n.2, p. 63-83, out. 2016.

FERREIRA, Naura S. Carapeto (org.) Gestão Democrática da Educação: atuais tendências, novos desafios. 6.ed. São Paulo: Cortez, 2008. 
FERREIRA, Naura S. Carapeto; AGUIAR, Márcia Ângela da S. (org.). Gestão da Educação: impasses, perspectivas e compromissos. 7. ed. Sáo Paulo: Cortez, 2009.

DE FREITAS, Luiz Carlos. Os reformadores empresariais da educação: da desmoralização do magistério à destruição do sistema público de educação. Educação \& Sociedade, São Paulo, v. 33, n. 119, São Paulo, p. 379-404, abr/jun. 2012.

GATTI, Bernadete. Implicaçóes e Perspectivas da Pesquisa Educacional no Brasil contemporâneo. Cadernos de Pesquisa, São Paulo, n.113, p.65-81, jul. 2001.

GOHN, M. da G. M. A Pesquisa na Produção do Conhecimento: questôes metodológicas. ECCOS - Revista Científica, São Paulo, v. 7, n. 2, p. 253-274, jul./dez. 2005.

GONÇALVES, Waldir Lourenço. Um Desafio para o Pesquisador: a formulação do problema de pesquisa. Contrapontos, Itajaí, n. 5, p. 237-250, maio/ago. 2002.

JIMENEZ, Emmanuel; LOCKHEED, Marlaine. Public and Private Secondary Education in Developing Countries: a comparative stude. World Bank (discussion papers, 309). Washington, 1995.

KOSIK, Karel. Dialética do Concreto. Rio de Janeiro: Paz e Terra, 1984.

KUHLMANN JÚNIOR, Moysés. Produtivismo acadêmico, publicação em periódicos e qualidade das pesquisas. Cadernos de Pesquisa, Sáo Paulo, v. 45, n. 158, p. 838-855, out./dez. 2015.

MACEDO, Elizabeth. Cultura performativa e pesquisa em educação: desafios para a ação política. Cadernos de Pesquisa, São Paulo, v. 45, n. 158, p. 752-774, out./dez. 2015.

MELLO, Guiomar Namo de. Cidadania e competitividade: desafios educacionais do terceiro milênio. 3. ed. São Paulo: Cortez, 1994.

MOREIRA, Antonio Flávio. A cultura da performatividade e a avaliação da pósgraduação em educação no Brasil. Educação em Revista, Belo Horizonte, v. 25, n. 3, p. 23-42, dez. 2009.

NEVES, Lúcia M. Wanderley (org.). A Nova Pedagogia da Hegemonia: estratégias do capital para educar o consenso: São Paulo: Xamá, 2005.

NEVES, Lúcia M. Wanderley; SANT'ANNA. Ronaldo. Gramsci, o Estado educador e a nova pedagogia da hegemonia In.: NEVES, Lúcia M. Wanderley (org.). A Nova Pedagogia da Hegemonia: estratégias do capital para educar o consenso: São Paulo: Xamã, 2005.p. 19-39.

OLIVEIRA, Dalila Andrade (org.). Gestão Democrática da Educação: desafios contemporâneos. 9. ed. Petrópolis, RJ: Vozes, 2009.

POUlANTZAS, Nicos. O Estado, o Poder, o Socialismo. Rio de Janeiro: Graal, 1981. 
SÁNCHEZ GAMBOA. Pesquisa Qualitativa: superando tecnicismos e falsos dualismos. Contrapontos, Itajaí (SC), v. 3, n. 3, p.393-405, set./dez. 2003.

SEVERINO, Antônio Joaquim. A Pesquisa em Educação: a abordagem crítico-dialética e suas implicações na formação do educador. Revista de Educação da Univali, Itajaí (SC), n. 1, p. 11-22, jan./jun. 2001.

SEVERINO, Antônio Joaquim. Pós-Graduação e Pesquisa: o processo de produção e de sistematização do conhecimento. Revista Diálogo Educacional. Curitiba, v. 9, n. 26, p. 13-27, jan./abr. 2009.

VAN ZANTEN, Agnès. Pesquisa Qualitativa em Educação: pertinência, validez e generalização. Perspectiva, Florianópolis, v. 22, n. 01, p. 25-45, jan./jun. 2004.

Recebido em 2 dez. 2017 / Aprovado em Io jan. 2018

\section{Para referenciar este texto:}

OLIVEIRA, R. A pesquisa em educação: a gestão educacional como tema do debate. EccoS - Revista Científica, São Paulo, n. 48, p. 273-294. jan./mar. 2019. Disponível em: <https://doi.org/I0.5585/EccoS.n48.8109>. 